\title{
Pathological and virological findings in patients with persistent hypertransaminasaemia of unknown aetiology
}

\author{
C Berasain, M Betés, A Panizo, J Ruiz, J I Herrero, M-P Civeira, J Prieto
}

\begin{abstract}
Background-The histopathological spectrum and role of hepatitis viruses in cases of hypertransaminasaemia of unknown aetiology have not been correctly analysed in a sufficiently large number of patients. Methods-We studied 1075 consecutive patients referred for liver biopsy because of elevation of alanine aminotransferase (ALT) levels for more than six months. From this population we selected those cases in whom the aetiology could not be defined from clinical, biochemical, and serological data obtained before biopsy. In these patients liver biopsies were reviewed, and hepatitis $B$ virus (HBV)-DNA and hepatitis $C$ virus (HCV)-RNA were assayed in serum by polymerase chain reaction (PCR). Serum hepatitis G virus (HGV)-RNA was determined by PCR in 74 patients.
\end{abstract}

Results-Of 1075 patients studied, the cause of the increased serum ALT levels remained elusive after appropriate testing in 109 patients $(\mathbf{1 0 . 1 \% )}$. Liver biopsies from these patients showed non-specific changes in $32.7 \%$ of cases, non-alcoholic steatohepatitis (NASH) in $15.8 \%$, and chronic hepatitis or cirrhosis in $51.5 \%$. HBV-DNA and/or HCV-RNA was detected more frequently in cryptogenic liver disease than in healthy blood donors $(26.7 \% v$ $3.4 \%$; $<0.001)$. HGV-RNA was found in only one patient. The proportion of cases with detectable HBV-DNA or HCV-RNA was $14.3 \%$ in patients with non-specific changes or NASH, $30.7 \%$ in patients with chronic hepatitis, and $61.5 \%$ in patients with cirrhosis. Cirrhosis was found more frequently in patients with positive $\mathrm{HBV}$ DNA and/or HCV-RNA in serum than in those who tested negatively $(p=0.005)$.

Conclusions-In our series, patients in whom biochemical and serological data did not determine the aetiology of the disease represented $10 \%$ of all cases referred for liver biopsy for persistent elevation of serum transaminases. Approximately 50\% of patients had chronic hepatitis or cirrhosis and the remainder had NASH or non-specific changes. Occult viral infections were found in a high proportion of cases in the first group and in a low percentage of patients in the second. (Gut 2000;47:429-435)

Keywords: cryptogenic liver disease; cryptogenic hepatitis; hepatitis B virus; hepatitis C virus; hepatitis $\mathrm{G}$ virus; non-alcoholic steatohepatitis
In most patients with persistent abnormal liver biochemistry, clinical data and serological tests allow identification of the causative factor or disease entity responsible for liver damage. The aetiological search includes investigation of alcohol abuse or exposure to drugs or other toxins, detection of hepatitis $\mathrm{B}$ virus (HBV) surface antigen $(\mathrm{HBsAg})$ or antibodies against hepatitis C virus (HCV), assays for autoantibodies, ceruloplasmin, alpha ${ }_{1}$ antitrypsin, serum ferritin, and transferrin saturation, and study of other metabolic disorders or systemic diseases (such as morbid obesity, diabetes with deficient glycaemic control, or thyroid dysfunction) which can affect the liver. However, in some subjects with persistent alteration of liver enzymes the cause of the disturbance cannot be established on the basis of these clinical and analytical data. These cases are referred to as cryptogenic chronic liver disease. The prevalence and histopathological spectrum of this entity have not been analysed in detail. In our study, we investigated the histological findings and implication of hepatitis viruses in cases referred for liver biopsy as a result of persistent elevation of transaminases in whom clinical, biochemical, and serological testing prior to histological sampling could not define the aetiology of the disease.

The advent of the polymerase chain reaction (PCR) allowed detection of HBV-DNA or HCV-RNA in patients who lacked HBsAg or anti-HCV antibodies. ${ }^{1-4}$ However, the significance and prevalence of occult viral infections in cryptogenic liver disease remains controversial. Thus while some studies have found $67 \%$ of HCV-RNA in whole blood from subjects with cryptogenic chronic hepatitis or cirrhosis, ${ }^{3}$ other investigators failed to detect HCV-RNA in the liver ${ }^{5}$ or serum ${ }^{6}$ from these patients. In contrast, while in some series HBV-DNA could not be detected in the serum of HBV seronegative patients with cryptogenic hepatitis ${ }^{7}$ or cirrhosis, in other series it was found in $14-85 \%^{4-12}$ of such cases. The low number of cases analysed in most reports, variability of criteria used to categorise patients, together with differences in techniques and material tested, and the diversity in geographic origin of the reported series, have contributed to our lack of knowledge of the pathogenic role of

Abbreviations used in this paper: HBV, hepatitis B virus; $\mathrm{HCV}$, hepatitis $\mathrm{C}$ virus; $\mathrm{HGV}$, hepatitis $\mathrm{G}$ virus; ALT, alanine aminotransferase; NASH, non-alcoholic steatohepatitis; $\mathrm{HBsAg}$, hepatitis B virus surface antigen; PCR, polymerase chain reaction; RT-PCR, reverse transcription-PCR; HIV, human immunodeficiency virus. 
known hepatitis viruses in cryptogenic liver diseases. In addition, most studies on chronic liver disease of unknown aetiology have focused on specific histopathological entities (chronic hepatitis and/or cirrhosis) and not on the broader spectrum of patients with hepatic disease of unknown causes who are referred for liver biopsy because of persistent abnormalities of liver biochemistry.

In this study we analysed 1075 consecutive patients who underwent liver biopsy because of persistent abnormalities in liver enzymes. From this group we selected those cases in whom clinical, biochemical, and serological screening before biopsy did not identify the aetiology of the liver lesion. In these cases the biopsy was reviewed blindly, and the role of occult infection by HBV, HCV, and hepatitis $\mathrm{G}$ virus (HGV) was established by determining HBVDNA, HCV-RNA, and HGV-RNA in serum using PCR.

\section{Material and methods}

PATIENTS

Patients with liver disease of unknown cause were identified among 1075 consecutive patients who underwent liver biopsy in our liver unit between 1991 and 1997. They were identified as cases with a persistent increase in alanine aminotransferase (ALT) ( $>1.5$ times the upper limit of normal on at least two different occasions over a minimum period of six months) and who met the following criteria: (1) absence of HBsAg and anti-HCV antibodies in serum; (2) ferritin, alpha ${ }_{1}$ antitrypsin, and ceruloplasmin levels within the normal range; (3) antinuclear, antimitochondrial, and antismooth muscle antibodies at a titre of $\leqslant 1 / 80$; (4) ethanol intake less than $80 \mathrm{~g} /$ day; (5) absence of treatment with potentially hepatotoxic drugs; (6) negative human immunodeficiency virus (HIV) serology; (7) absence of decompensated diabetes, thyroid dysfunction, morbid obesity (defined as body mass index $\geqslant 35 \mathrm{~kg} / \mathrm{m}^{2}$ ) or other systemic diseases which might affect the liver, including severe hyperlipidaemia (cholesterol or triglyceride serum levels greater than $350 \mathrm{mg} / \mathrm{dl}$ ); and (7) absence of focal intrahepatic lesions or biliary abnormalities at ultrasonography.

Epidemiological data (previous history of acute hepatitis, transfusion, intravenous drug addiction, acupuncture, tattooing, etc), clinical data (patient age, sex, body mass index (body weight in $\mathrm{kg} /$ height in metres)), and biochemical parameters, including glucose, triglycerides, cholesterol, and proteinogram were recorded. Fifty eight consecutive sex and age matched healthy blood donors from the hospital blood bank were used as controls.

\section{LIVER HISTOPATHOLOGY}

Liver biopsies were reviewed by an independent pathologist who was blinded to the serological and biochemical patient data. Specimens were fixed in $10 \%$ neutral buffered formalin and stained with haematoxylin and eosin, trichrome, orcein, and periodic acidSchiff with diastase digestion for reticulin and iron. Different histological parameters were evaluated including fibrosis, portal inflammation, piecemeal necrosis, lobular inflammation, lobular necrosis, steatosis, cholestasis, bile duct damage, sinusoidal dilation, and iron deposition. These histological features were graded as absent, sparse-mild, or moderate-severe. Fibrosis was graded on a scale of absent, sparsemild, or severe bridging-cirrhosis. According to these data, liver biopsies were classified into three groups: (1) chronic hepatitis and cirrhosis according to international criteria ${ }^{13}$; chronic hepatitis in turn was subclassified into mild (lymphocytic inflammation in more than one third of portal tracts, leaving the parenchymal limiting plate preserved, with minimal intraacinous changes), moderate (dense inflammatory portal infiltration with piecemeal necrosis involving less than $50 \%$ of the circumference of most portal tracts but still restricted to periportal areas), or severe (piecemeal necrosis in the periportal region involving more than $50 \%$ of the circumference of most portal tracts, and along fibrous septa); (2) non-alcoholic steatohepatitis (NASH): moderate-gross macrovesicular fatty changes with hepatocyte degeneration and ballooning (with or without Mallory hyaline bodies) or fibrosis in zone $3^{14}{ }^{15}$; and (3) non-specific/minimal changes: a variety of mild abnormalities including intrahepatocytic cholestasis, steatosis, sinusoidal dilation, and mild lobular inflammation or necrosis.

Immunoperoxidase staining for HBV surface and core proteins was performed in liver samples of all PCR-B positive cases.

\section{SEROLOGY}

HBsAg, anti-HBc (IgG), and anti-HBs were tested by standard ELISA kits (Cobas Core, Roche, Madrid). Anti-HCV antibodies were detected using the ELISA 3 test (OrthoClinical Diagnostics GmbH, Germany). AntiHIV antibodies were tested by ELISA (Cobas Core, Roche, Madrid). Antiendomysium antibodies were tested using the indirect fluorescent antibody procedure (MARDX Diagnostics, Inc., California, USA).

PCR ASSAY FOR HBV DNA

DNA was extracted from $200 \mu$ of serum using the High Pure Viral Nucleic Acid Kit (Boehringer Mannheim, Mannheim, Germany). Every extraction and PCR set included 12 samples: seven serum samples to be tested, three water samples as negative controls to detect cross contamination, and two positive controls to establish sensitivity, corresponding to two dilutions of serum from a HBsAg positive patient representing 300 and $30 \mathrm{HBV}$ particles, respectively. Nested PCR was performed using the following as primers: HBV-S1 (nt 222-241), HBV-S2 (nt 757-738), HBV-S3 (324-343), and HBV-S4 (707-688). ${ }^{16}$ Briefly, half of the DNA volume was amplified for 36 cycles $\left(95^{\circ} \mathrm{C}\right.$ for 20 seconds, $60^{\circ} \mathrm{C}$ for 15 seconds, and $72^{\circ} \mathrm{C}$ for 25 seconds) followed by a final extension at $72^{\circ} \mathrm{C}$ for 10 minutes in a total reaction mixture of $30 \mu \mathrm{l}$ containing 10 $\mathrm{mM}$ Tris $\mathrm{HCl}, \mathrm{pH} 8.3,1.5 \mathrm{mM} \mathrm{MgCl}, 50 \mathrm{mM}$ $\mathrm{KCl}, 400 \mathrm{mM} \mathrm{dNTP}, 1.5 \mathrm{U}$ of Taq polymerase 
(Boehringer Mannheim), and $0.15 \mathrm{mM}$ of each outer primer HBV-S1 and HBV-S2. The first PCR product $(1 \mu \mathrm{l})$ was mixed with $9 \mu \mathrm{l}$ of the reaction mixture (as described above) containing each of the inner primers HBV-S3 and HBV-S4. A second round of PCR was performed with the same protocol and the $10 \mu \mathrm{l}$ of reaction mixture were loaded on a $2 \%$ agarose gel for electrophoresis. All precautions for avoiding PCR contamination were followed stringently. Each positive result was confirmed by a second independent determination. DNA from liver was extracted using the DNAzol Reagent (Life Technologies, Gibco BRL, Gaithersburg, USA). DNA ( $1 \mu \mathrm{g})$ was used for amplification with the PCR protocol described above. The sensitivity of the assay was $10^{3}$ genome eq $/ \mathrm{ml}$.

CLONING AND SEQUENCE ANALYSIS

Positive samples were loaded after amplification on a $2 \%$ agarose gel. Bands were excised from the gel and DNA was purified using the Geneclean II kit (Bio 101, Vista, California, USA). Aliquots were cloned into the pCR2.1TOPO plasmid using the TOPO-TA cloning kit (Invitrogen, Carlsbad, California, USA). At least 10 white colonies were tested for the presence of the insert by PCR. Minipreps were performed using the Qiaprep Spin Miniprep kit (Qiagen, Hilden, Germany). A minimum of five clones were sequenced with M13 primers using the dRhodamine Terminator Cycle Sequencing Ready Reaction Kit in an ABI PRISM 310 Genetic Analyzer (PE Applied Biosystems, Foster City, California, USA). Bidirectional sequencing was performed to confirm mutations. Sequences from each patient were compared using the Clustal program and each representative sequence was compared for homology in the GenBank.

RT-PCR ASSAY FOR DETECTION OF HCV RNA RNA was extracted from sera and liver using the Ultraspec Reagent (Biotecx Laboratories, Inc., Houston, Texas, USA). RT-PCR was performed using primers from 5'UTR as described previously. ${ }^{17}$

PCR ASSAY FOR DETECTION OF HGV RNA

RNA was extracted from sera using the Ultraspec Reagent (Biotecx Laboratories, Inc., Houston, Texas, USA). HGV-RNA was detected by RT-PCR using a commercial kit (Hepatitis G Virus-Primer and Capture Probe Set; Boehringer Mannheim).

STATISTICAL ANALYSIS

Fisher's exact test was used to compare proportions and the Student's $t$ test to compare continuous variables. The Mann-Whitney U test was used to compare non-parametric variables in independent samples. All statistical tests were two tailed.

\section{Results}

PREVALENCE OF CRYPTOGENIC LIVER DISEASE

AMONG PATIENTS WHO UNDERWENT LIVER BIOPSY BECAUSE OF PERSISTENT ALT ELEVATION

We investigated 1075 patients referred for liver biopsy because of persistent (more than six months) elevation of serum transaminases. In 966 cases $(89.8 \%)$, clinical, biochemical, and serological testing allowed identification of the disease entity or aetiology of the process while in 109 patients $(10.1 \%)$ the cause of the hepatic lesion was not identified before the liver biopsy was performed, despite an appropriate diagnostic work up (see material and methods). Of the 109 cases of liver disease of unknown cause, serum samples from eight patients were not available. Thus 101 patients (71 male, 30 female, mean age 45.8 (13.5) years) were included in the study.

HISTOPATHOLOGICAL FINDINGS IN CRYPTOGENIC LIVER DISEASE

Liver biopsies from the 101 cases with hypertransaminasaemia of unknown aetiology included in the study were reviewed blindly by the same pathologist. Examination of the liver tissue showed non-specific changes in 33 subjects $(32.7 \%)$ and NASH in 16 patients $(15.8 \%)$. All patients with NASH presented moderate to severe steatosis in liver tissue while in the group recorded as non-specific changes, moderate to severe steatosis (simple fatty liver) was observed in four cases and mild steatosis in 17 (other criteria for NASH are given in material and methods). Chronic hepatitis was found in 39 patients (38.6\%), being mild in 11 and moderate/severe in 28. Cirrhosis was present in 13 subjects $(12.9 \%)$. These diagnoses were coincident with the initial report except that four cases previously recorded as simple fatty liver were included in the NASH group and four cases diagnosed as minimal changes were considered as mild chronic hepatitis after histological review.

PREVALENCE OF HBV-DNA, HCV-RNA, AND HGV-RNA IN CRYPTOGENIC LIVER DISEASE The prevalence of HBV-DNA and/or HCVRNA was significantly higher in patients with hepatic disease of unknown cause than in healthy blood donors $(26.7 \% \quad v \quad 3.4 \%$; $\mathrm{p}<0.001)$. HBV-DNA and HCV-RNA were detected in the serum of $19(18.8 \%)$ and nine $(8.9 \%)$ patients with cryptogenic disease, respectively. One healthy blood donor was HBV-DNA positive $(1.7 \%)$ and another HCVRNA positive $(1.7 \%)$. Only one patient and none of the controls showed positivity for both viral genomes (table 1). In the group of 966 cases (representing $89.9 \%$ of the total number of 1075 patients studied) in which the aetiology of the liver lesion was established by conventional diagnostic tests, 96 (9.9\%) had HBV infection, $548(56.7 \%)$ had HCV infection, and $10(1.03 \%)$ were infected by both HCV and HBV. Therefore, occult HBV infection was more prevalent than occult $\mathrm{HCV}$ infection despite the fact that seropositive hepatitis $\mathrm{C}$ is more prevalent than HbsAg positive liver disease in our geographic area.

We tested 74 patients for the presence of HGV-RNA: only one patient $(1.3 \%)$ was found to be positive. This patient was negative for HBV-DNA and HCV-RNA. HGV-RNA was not present in any of the healthy blood donors tested. 
Table 1 Prevalence of HBV-DNA and HCV-RNA in patients with cryptogenic liver disease $(n=101)$ and in healthy controls $(n=58)$

\begin{tabular}{lll}
\hline $\begin{array}{l}H B V-D N A / \\
H C V-R N A\end{array}$ & $\begin{array}{l}\text { Cryptogenic } \\
\text { (No (\%)) }\end{array}$ & $\begin{array}{l}\text { Healthy controls } \\
\text { (No (\%)) }\end{array}$ \\
\hline $\mathrm{P} / \mathrm{P}$ & $1(1)$ & 0 \\
$\mathrm{P} / \mathrm{N}$ & $18(17.8)$ & $1(1.7)$ \\
$\mathrm{N} / \mathrm{P}$ & $8(7.9)$ & $1(1.7)$ \\
$\mathrm{N} / \mathrm{N}$ & $74(73.3)$ & $56(96.5)$ \\
\hline
\end{tabular}

$\mathrm{P}$, positive cases; $\mathrm{N}$, negative cases.

In five HBV-DNA positive and two $\mathrm{HCV}$ RNA positive subjects, investigation of these viral sequences in serum was repeated in samples obtained on three or more occasions. In three of the former group and in one of the latter, a positive PCR test was obtained in two or more samples. These data indicate that in our patients with positive HBV-DNA or HCVRNA, viral load was low and viraemia was detectable only intermittently.

Four patients with cryptogenic cirrhosis underwent orthotopic liver transplantation (two who tested positive for serum HBV-DNA and two who tested negative). In these four cases we studied the presence of HBV-DNA and HCV-RNA in the explanted liver and in post-transplantation serum (1-28 weeks after liver transplantation). HBV-DNA was detected in the explanted liver only in the two cases who were serum HBV-DNA positive before transplantation. One of these patients continued to have detectable HBV-DNA in serum after transplantation. HCV-RNA was negative in both post-transplantation serum and explanted liver in all four cases.

MARKERS OF HEPATITIS VIRUS IN CRYPTOGENIC LIVER DISEASE

The presence of anti-HBV antibodies was tested in 98 patients. As shown in table 2 $30.6 \%$ patients showed positivity for either anti-HBc or anti-HBs, or both. Fifty per cent of cases with positive serum HBV-DNA and $26.2 \%$ with negative HBV-DNA had positive HBV antibodies. These differences were not statistically significant. Interestingly, all HCVRNA positive cases showed negative anti-HBV antibodies (table 2). These results (and the fact that we found positivity for both HBV-DNA and HCV-RNA in only one case) indicate that HBV positive and HCV positive cases represent two serologically differentiated groups. $\mathrm{HBs}$ and $\mathrm{HBc}$ proteins were investigated in liver biopsies by immunohistochemistry. All cases were found to be negative. Finally, it is worth noting that for all viral markers (HCVRNA, HBV-DNA, and anti-HBV antibodies), only 52 of 98 cases lacked serological signs of contact with hepatitis viruses.

CLINICAL AND BIOCHEMICAL FINDINGS IN CRYPTOGENIC LIVER DISEASE ACCORDING TO THE PRESENCE OR ABSENCE OF HBV-DNA OR HCV-RNA IN SERUM

We compared clinical and biochemical data from patients with liver disease of unknown cause and who were positive for HBV-DNA or HCV-RNA with those in whom viraemia was not detected. As shown in table 3, patients
Table 2 Presence of anti-HBc and anti-HBs antibodies in patients with cryptogenic liver disease

\begin{tabular}{llll}
\hline HBV-DNA & Anti-HBc & Anti-HBs & $n$ \\
\hline $\mathrm{P}$ & $\mathrm{P}$ & $\mathrm{P}$ & 5 \\
$\mathrm{P}$ & $\mathrm{P}$ & $\mathrm{N}$ & 1 \\
$\mathrm{P}$ & $\mathrm{N}$ & $\mathrm{P}$ & 3 \\
$\mathrm{P}$ & $\mathrm{N}$ & $\mathrm{N}$ & $9^{\star}$ \\
$\mathrm{P}$ & $\mathrm{nt}$ & $\mathrm{nt}$ & 1 \\
$\mathrm{~N}$ & $\mathrm{P}$ & $\mathrm{P}$ & 14 \\
$\mathrm{~N}$ & $\mathrm{P}$ & $\mathrm{N}$ & 2 \\
$\mathrm{~N}$ & $\mathrm{~N}$ & $\mathrm{P}$ & $5 \dagger$ \\
$\mathrm{N}$ & $\mathrm{N}$ & $\mathrm{N}$ & $59 \ddagger$ \\
$\mathrm{N}$ & $\mathrm{nt}$ & $\mathrm{nt}$ & $2^{\star}$
\end{tabular}

$\mathrm{P}$, positive cases; $\mathrm{N}$, negative cases; $\mathrm{n}$, number of cases; $\mathrm{nt}$, not tested.

${ }^{\star}$ One patient in each group was HCV-RNA positive.

†One patient was vaccinated.

$\ddagger$ Seven patients were HCV-RNA positive and one patient was HGV-RNA positive.

from the first group were significantly older (50.6 (14.3) $v 43.9(12.8)$ years; $\mathrm{p}=0.03)$ and showed clinical signs of decompensated cirrhosis more frequently $(25.9 \%$ v $5.4 \%$; $\mathrm{p}=0.007)$ than patients in whom both HBVDNA and HCV-RNA were negative. The number of patients with dyslipaemia (elevated serum cholesterol and/or triglyceride levels) was significantly higher in patients without detectable viraemia than in positive cases $(\mathrm{p}=0.04)$, probably reflecting a higher proportion of NASH among these patients. Also, ALT levels were significantly higher in patients who tested negative for HBV-DNA or HCVRNA than in cases with detectable viraemia, but no significant differences in other clinical and biochemical data (including glycaemia, obesity, gamma globulin levels, presence of low titres of autoantibodies, parenteral exposure, or past history of acute hepatitis) were observed. With respect to cases diagnosed as $\mathrm{NASH}$, none showed fasting glycaemia in excess of $130 \mathrm{mg} / \mathrm{dl}$, in only two patients did serum cholesterol exceed $300 \mathrm{mg} / \mathrm{dl}$, and in only three cases were triglyceride levels greater than $300 \mathrm{mg} / \mathrm{dl}$ with $332 \mathrm{mg} / \mathrm{dl}$ being the highest value (patients with decompensated diabetes, morbid obesity, and severe dyslipaemia were excluded from the category of hypertransaminasaemia of unknown aetiology). Antiendomysium antibodies were tested in 64 patients from the first group and in 10 from the second (cases with negative and positive viraemia, respectively); the test was negative in all cases, indicating a low percentage of occult coeliac disease in our series of cryptogenic liver disease. There were no significant differences in clinical or biochemical parameters between patients with positivity for HBV-DNA and those with positivity for HCV-RNA.

PREVALENCE OF HBV-DNA OR HCV-RNA IN THE DIFFERENT HISTOPATHOLOGICAL FORMS OF LIVER DAMAGE IN PATIENTS WITH CRYPTOGENIC LIVER DISEASE

With regard to the prevalence of HBV-DNA or HVC-RNA in the different histopathological forms of liver damage in patients with cryptogenic liver disease, viraemia was found in $14.3 \%$ of patients with NASH or non-specific changes, in $30.7 \%$ of those with chronic hepa- 
Table 3 Clinical, biochemical, and histological features of patients with cryptogenic liver disease according to the presence of occult hepatitis viruses

\begin{tabular}{|c|c|c|c|}
\hline & $\begin{array}{l}H B V-D N A \text { and/or } \\
H C V-R N A \text { positive } \\
(n=27)\end{array}$ & $\begin{array}{l}H B V-D N A \text { and } \\
H C V-R N A \text { negative } \\
(n=74)\end{array}$ & $p$ Value \\
\hline Age (y) & $50.67(14.34)$ & $43.99(12.84)$ & 0.03 \\
\hline $\operatorname{Sex}(M / F)$ & $19 / 8$ & $52 / 22$ & $>0.2$ \\
\hline \multicolumn{4}{|l|}{ Risk factors ${ }^{1}$} \\
\hline Transfusion & $1 / 24(4.2 \%)$ & $4 / 67(6 \%)$ & $>0.2$ \\
\hline History of acute hepatitis & $2 / 24(8.3 \%)$ & $13 / 57(22.8 \%)$ & $>0.2$ \\
\hline Anti-HBs and/or anti-HBc & $9 / 25(36 \%)$ & $20 / 73(27.4 \%)$ & $>0.2$ \\
\hline Clinical symptoms & & & 0.007 \\
\hline Decompensated cirrhosis & $7(25.9 \%)$ & $4(5.4 \%)$ & \\
\hline Non-specific symptoms & $20(74.1 \%)$ & $70(94.6 \%)$ & \\
\hline Dyslipaemia $^{2}$ & $7(25.9 \%)$ & $36(48.7 \%)$ & 0.04 \\
\hline Hyperglycaemia & $5(7.4 \%)$ & $12(16.2 \%)$ & $>0.2$ \\
\hline Obesity & $9(33.3 \%)$ & $14(18.9 \%)$ & 0.2 \\
\hline Gamma globulin $(\mathrm{g} / \mathrm{dl})^{3}$ & $1.38(0.46)$ & $1.21(0.3)$ & 0.08 \\
\hline \multicolumn{4}{|l|}{ Liver function tests ${ }^{3}$} \\
\hline AST/GOT (UI/l) & $38(25.9)$ & $32(36.4)$ & $>0.2$ \\
\hline ALT/GPT (UI/l) & $52.5(32.4)$ & $72.8(64.7)$ & 0.007 \\
\hline No patients with mean ALT $>1.5$ normal & $11(40.7 \%)$ & $56(75.7 \%)$ & 0.001 \\
\hline Alkaline phosphatase (UI/l) & $185.2(94.9)$ & $190.8(112)$ & $>0.2$ \\
\hline GGT (UI/l) & $81.1(75.5)$ & $109.5(101.8)$ & 0.08 \\
\hline Autoantibodies (ANA, ASMA) $(\leqslant 1 / 80)$ & $5(18.5 \%)$ & $13(17.6 \%)$ & $>0.2$ \\
\hline Liver biopsy & & & 0.01 \\
\hline Non-specific changes & $5(18.5 \%)$ & $28(37.8 \%)$ & \\
\hline NASH & $2(7.4 \%)$ & $14(18.9 \%)$ & \\
\hline Chronic hepatitis & $12(44.4 \%)$ & $27(36.5 \%)$ & \\
\hline Cirrhosis & $8(29.6 \%)$ & $5(6.8 \%)$ & \\
\hline
\end{tabular}

Values are mean (SD) or number (\%).

${ }^{1}$ Number of positive patients/number of patients studied.

${ }^{2}$ Levels of cholesterol and/or tryglicerides above the normal limit in at least two determinations.

${ }^{3}$ The individual numbers used to calculate the mean were the average for all determinations on

each patient (mean 5, range 2-24). Normal values: gamma globulin $<1.34 \mathrm{~g} / \mathrm{dl}$; AST/GOT $<25$

$\mathrm{UI} / 1$; ALT/GPT <29 UI/1; alkaline phosphatase <207 UI/1; GGT <38 UI/1.

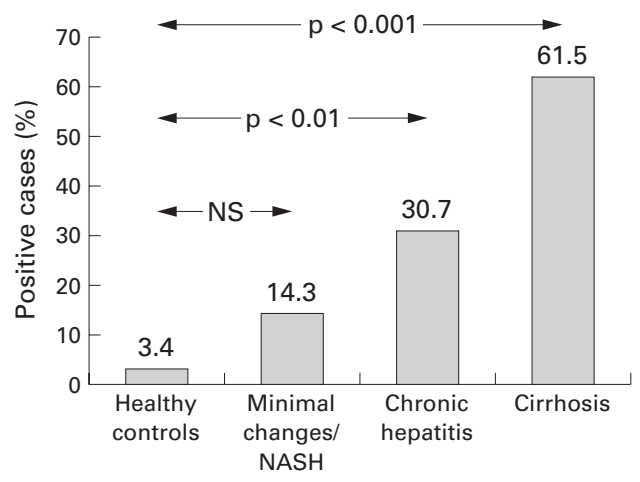

Figure 1 Percentage of patients with cryptogenic liver disease and healthy controls who had detectable hepatitis $B$ virus-DNA and/or hepatitis $C$ virus-RNA by polymerase chain reaction in serum. NASH, non-alcoholic steatohepatitis.

titis, and in $61.5 \%$ of subjects with cirrhosis (fig 1). In patients with non-specific changes or $\mathrm{NASH}$, the prevalence of viraemia was not significantly different from that found in controls $(p=0.08)$. In contrast, in patients with chronic hepatitis or cirrhosis, the percentage of cases with positive HBV-DNA or HCV-RNA was significantly higher than in healthy controls $(38.5 \%$ v $3.4 \% ; \mathrm{p}<0.001)$ or patients with non-specific changes or NASH $(38.5 \% v$ $14.3 \% ; \mathrm{p}=0.007)$. Cirrhosis was significantly more prevalent in the group of patients with detectable HBV-DNA or HCV-RNA than in cases with negative viraemia $(29.6 \%$ v $6.8 \%$; $\mathrm{p}=0.005$ ) (table 3). No significant differences in liver histopathology were found between subjects with anti-HBV antibodies and those without anti-HBV antibodies in serum.
SEQUENCE OF HBV IN PATIENTS WITH POSITIVE HBV-DNA IN SERUM

The HBV fragment amplified by PCR comprised the immunodominant "a" determinant of HBsAg as well as 383 nucleotides from the polymerase gene. This fragment was cloned and sequenced in 17 of the $19 \mathrm{HBV}-\mathrm{DNA}$ positive patients. In all cases a minimum of five clones per sample were analysed.

All HBV sequences corresponded to genotype A serotype adw2 (50\% of samples) or to genotype D serotype ayw (50\% of samples). No differences were found in clinical, biochemical, or pathological findings in relation to the HBV genotype present in serum.

Sequences in seven patients showed total homology with wild-type sequences published previously. In the remaining 10 patients at least one nucleotide change was found, two of which were associated with deletion of one and six nucleotides, respectively, in some of the clones. In eight of these patients two or three different HBV sequences were found. The observed mutations caused at least one amino acid change in both polymerase and HBsAg genes in nine patients and one amino acid change in the polymerase gene in the remaining patient. In three cases the changes affected the "a" determinant.

\section{Discussion}

In patients who underwent liver biopsy because of persistent alteration of liver biochemistry, the aetiology of the liver lesion could not be determined from clinical, biochemical, or serological data obtained prior to the biopsy in 10\% of cases. This value is similar to the reported prevalences of $9.2 \%$ and $8.2 \%$ for cryptogenic hypertransaminasaemia observed in other European series. ${ }^{18} 19$

There is little information on the spectrum of pathological liver changes which can be found in patients with hypertransaminasaemia of unknown aetiology. ${ }^{20}$ This is mainly because most histological studies in large series of patients were performed before the discovery of hepatitis C. Most recent reports on cryptogenic chronic liver disease have focused on cases with chronic hepatitis and/or cirrhosis. $^{62122}$ In our work, only about half $(51.5 \%)$ of our patients had chronic hepatitis or cirrhosis while the remaining patients $(48.5 \%)$ exhibited non-specific changes or NASH. These two groups of pathological entities (chronic hepatitis or cirrhosis on the one hand and non-specific changes or NASH on the other) appear to correspond to different causes of liver damage as the prevalence of $\mathrm{HBV} / \mathrm{HCV}$ viraemia was found to be high in the former group and low in the latter. Patients who were found to have NASH on histological examination entered the group of hypertransaminasaemia of unknown aetiology because the categorisation "cryptogenic" was made without knowledge of the liver biopsy results. Although NASH could be anticipated in cases of morbid obesity, severe dyslipaemia, or diabetes with deficient or deterioration in glycaemic control, we considered these conditions exclusion criteria for hypertransamina- 
saemia of unknown cause. Mild to moderate metabolic disorders, as those present in our cases of cryptogenic liver disease with NASH (see results), are highly prevalent in the population and are not generally considered as a cause of liver dysfunction in the absence of histological study.

Different reports have indicated that low level replication of HBV and/or HCV may play a pathogenic role in a proportion of cases with cryptogenic hepatitis or cirrhosis. ${ }^{2389} \mathrm{Re}-$ cently, low levels of serum HBV-DNA were detected in patients with $\mathrm{HCV}$ infection lacking other serological HBV markers. ${ }^{4}$ In our study, $27 \%$ of all cases with chronic hypertransaminasaemia of unknown aetiology were positive for either HBV-DNA or HCV-RNA. The presence of HBV-DNA in liver tissue in two transplanted cases who tested positive for HBV-DNA in a pretransplant serum sample and the absence of the HBV genome in the liver in two other cases who tested negative for HBV-DNA in serum before transplantation further support the implication of $\mathrm{HBV}$ in cryptogenic chronic liver damage in cases where HBV-DNA is detected in serum by PCR techniques. It has been reported that detection of HCV-RNA in whole blood is more sensitive than serum assays; ${ }^{3}$ on the other hand, it has been shown that HBV-DNA can be found in liver tissue in patients in whom viral sequences are not detectable in serum, even using sensitive techniques. ${ }^{42324}$ Thus it seems possible that participation of known hepatitis viruses in the aetiology of cryptogenic chronic hepatitis and cryptogenic cirrhosis might be higher than that observed in the present study. However, it should be noted that our results relate to a Mediterranean country with a high prevalence of hepatitis viruses in the general population and may not be applicable to other parts of the world, such us north west Europe, where hepatitis $\mathrm{B}$ and $\mathrm{C}$ are much less common.

Importantly, when pathological and virological data (which were performed blindly by independent observers) were pooled, we found that most patients $(74 \%)$ with positive viraemia (HBV-DNA or HCV-RNA) had chronic hepatitis or cirrhosis. As shown in fig 1, there was a progressive increase in the prevalence of viraemia as the severity of the liver lesion increased, with values of $3.4 \%$ in healthy blood donors, $14.3 \%$ in patients with NASH or non-specific changes, $30.7 \%$ in those with chronic hepatitis, and $61.5 \%$ in subjects with cirrhosis. These data support the specificity of our findings and strongly suggest the participation of occult $\mathrm{HBV}$ and $\mathrm{HCV}$ infections (HBV being more prevalent than $\mathrm{HCV}$ ) in the aetiology of cryptogenic hepatitis and cirrhosis. In patients with chronic hypertransaminasaemia of unknown aetiology the presence of viral genomes (HBV-DNA or HCV-RNA) in serum appears to predict a more severe disease. Thus patients with cryptogenic liver disease with positive viraemia had a higher prevalence of cirrhosis $(29.6 \%)$ than those cases who tested negative for HBV-DNA and HCV-RNA (6.8\%, $\mathrm{p}=0.005)$. Also, the former group of patients exhibited signs of decompensated cirrhosis more frequently than those with undetectable viraemia (table 3). These data are in accordance with reports showing a more aggressive course in cryptogenic cirrhosis when viral sequences can be detected in serum compared with patients who tested negative. ${ }^{3}$ Occult $\mathrm{HBV}$ infection has also been found to correlate significantly with cirrhosis in $\mathrm{HCV}$ infected patients suggesting that occult replication of $\mathrm{HBV}$ at low levels can accelerate the evolution to cirrhosis in patients with chronic $\mathrm{HCV}$ infection. ${ }^{4}$

Although low level replication of HBV may favour progression of the liver lesion the pathogenic relevance of antibodies to $\mathrm{HBV}$ in the absence of detectable HBV-DNA remains obscure. In fact, among patients with negative viraemia, there were no significant differences in liver histopathology between those with anti-HBV antibodies and those who tested negative.

A previous report has suggested that HBV genotype D is the "surviving" genotype after clearance of HbsAg. ${ }^{25}$ In our series, patients with cryptogenic liver disease were infected with HBV genotype D or HBV genotype A in a similar proportion and there was no correlation between genotype and clinical or pathological data. Sequencing of the amplified fragment of HBV-DNA showed mutations in 10 of the 17 cases analysed; these changes affected the "a" determinant of HBsAg in only three cases. It seems therefore that changes in other parts of the HBV genome may be responsible for persistent and low grade replication of $\mathrm{HBV}$ in these cases with occult viral infection. In fact, deletions in the $\mathrm{X}$ gene have been suggested to be responsible for the low level of replication in HBsAg negative patients with positive viraemia. ${ }^{126}$

HGV was present in only one case, indicating that this virus is not involved in cryptogenic chronic liver disease. This is in accordance with previous data which do not support the participation of $\mathrm{HGV}$ in cryptogenic hepatitis. ${ }^{27-29}$ Some reports have suggested that about $10 \%$ of cases of cryptogenic chronic hepatitis have features typical of autoimmune hepatitis but lack autoantibodies. ${ }^{30}$ Autoimmunity could be implicated in cases with cryptogenic chronic hepatitis or cirrhosis with negative viraemia but the high percentage of HBV-DNA or HCV-RNA positive cases in this study calls for caution when considering corticosteroid treatment in cryptogenic hepatitis. In these cases PCR tests for HBV-DNA and HCV-RNA should be performed before initiation of therapy. Although treatment with antiviral agents could be considered for cases with positive viraemia, controlled studies are needed to establish whether these patients can benefit from this form of therapy.

We wish to thank Celia Asensio, Beatriz Carte, Elena Saez, and Edurne Elizalde for technical support.

Grant support: J Vidal, JL Dominguez, and I Bemberg grants, and PIUNA grant from the University of Navarra.

1 Paterlini P, Driss F, Nalpas B, et al. Persistence of hepatitis B and hepatitis $C$ viral genomes in primary liver cancers from 
HBsAg-negative patients: a study of a low-endemic area. Hepatology 1993; 17:20-9.

2 Chung HT, Lai CL, Lok ASF. Pathogenic role of hepatitis B virus in hepatitis B surface antigen-negative decompensated cirrhosis. Hepatology 1995;22:25-9.

3 Schmidt WN, Wu P, Cederna J, et al. Surreptitious hepatitis $\mathrm{C}$ virus (HCV) infection detected in the majority of patients with cryptogenic chronic hepatitis and HCV antibody test. F Infect Dis 1997;176:27-33.

4 Cacciola I, Pollicino T, Squadrito G, et al. Occult hepatitis B virus infection in patients with chronic hepatitis $\mathrm{C}$ liver disease. N Engl f Med 1999; 341:22-6.

5 Geller SA, Nichols WS, Rojter SE, et al. Hepatitis C virus is not recoverable from liver tissue in cryptogenic cirrhosis: failure to identify hepatitis C virus-RNA using reverse transcription-mediated polymerase chain reaction. Pathol 1996;27:1161-5.

6 Kodali VP, Gordon SC, Silverman AL, et al. Cryptogenic liver disease in the United States: further evidence for non-A, non-B, and non-C hepatitis. Am $f$ Gastroenterol 1994;89: 1836-9.

7 Romeo R, Pol S, Demeret C, et al. Evidence of non-A, non-B, non-C infection in chronic hepatitis by polymerase chain reaction testing for hepatitis $\mathrm{B}$ and $\mathrm{C}$ viruses. F Hepatol 1995;22:125-9.

8 Huo TJ, Wu JC, Lee PC, et al. Sero-clearance of hepatitis B surface antigen in chronic carriers does not necessarily imply a good prognosis. Hepatology 1998; 28:231-6.

9 Liang TJ, Baruch Y, Ben-Porath E, et al. Hepatitis B virus infection in patients with idiopatic liver disease. Hepatology 1991;13:1044-51.

10 Zhang YY, Hansson BG, Kuo LS, et al. Hepatitis B virus DNA in serum and liver is commonly found in Chinese patients with chronic liver disease despite the presence of antibodies to HbsAg. Hepatology 1993;17:538-44.

11 Fukuda R, Ishimura N, Kushiyama Y, et al. Hepatitis B virus $\mathrm{X}$ gene mutation is associated with the majority of serologically "silent" non-b, non-c chronic hepatitis. Microbiol cally "silent" non-b, non-

12 Uchida T, Shimojima M, Gotoh K, et al. "Silent" hepatitis B virus mutants are responsible for non-A, non-B, non-C, non-D, non-E hepatitis. Microbiol Immunol 1994;38:28145.

13 International Working Party. Terminology of chronic hepatitis. Am $\mathcal{F}$ Gastroenterol 1995; 90:181-9.

14 Sheth SG, Gordon FD, Chopra S. Nonalcoholic steatohepatitis. Ann Intern Med 1997;126:137-45.

15 Bacon BR, Farahvash MJ, Janney CG, et al. Nonalcoholic steatohepatitis: an expanded clinical entity. Gastroenterology 1994;107:1103-9.

16 Ruiz J, Sangro B, Cuende JI, et al. Hepatitis B and C viral infections in patients with hepatocellular carcinoma. Hepatology 1992;16:637-41.
17 Gil B, Qian C, Riezu-Boj JI, et al. Hepatic and extrahepatic HCV RNA strands in chronic hepatitis C: different patterns of response to interferon treatment. Hepatology 1993;18:1050-4.

18 Volta U, De Franceschi L, Lari F, et al. Celiac disease hidden by cryptogenic hypertransaminasaemia. Lancet 1998; 352:26-9.

19 Sarrazin C, Hermann G, Roth WK, et al. Prevalence and clinical and histological manifestation of hepatitis G/GBV-C infections in patients with elevated aminotransferases of unknown etiology. F Hepatol 1997;27:276-83.

20 Mathiesen UL, Franzen LE, Fryden A, et al. The clinical significance of slightly to moderately increased liver transaminase values in asymptomatic patients. Scand 7 Gastroenterol 1999;34:85-91.

21 Goldstein NS, Kodali VP, Gordon SC. Histologic spectrum of cryptogenic chronic liver disease and comparison with chronic autoimmune and chronic type $\mathrm{C}$ hepatitis. $\mathrm{Am} \mathcal{F}$ Clin Pathol 1995;104:567-73.

22 Greeve M, Ferrel L, Kim M, et al. Cirrhosis of undefined pathogenesis: absence of evidence for unknown viruses or autoimmune processes. Hepatology 1993;17:593-8.

23 Fong TL, Bisceglie AM, Gerber MA, et al. Persistence of hepatitis B virus DNA in the liver after loss of HBsAg in chronic hepatitis B. Hepatology 1993;18:1313-18.

24 Loriot MA, Marcellin P, Walker F, et al. Persistence of hepatitis B virus DNA in serum and liver from patients with chronic hepatitis B after loss of HBsAg. F Hepatol 1997;27: 251-8.

25 Bahn A, Gerner P, Martiné U, et al. Detection of different viral strains of hepatitis B virus in chronically infected children after seroconversion from $\mathrm{HBsAg}$ to anti-HBs indicating viral persistence. $\mathcal{F}$ Hepatol 1997;27:973-97

26 Feitelson MA, Duan LX, Guo J, et al. X region deletion variants of hepatitis $B$ virus in surface antigen-negative infections and non-A, non-B hepatitis. F Infect Dis 1995;172:713-22.

27 Guilera M, Sáiz JC, López-Labrador FX, et al. Hepatitis G virus infection in chronic liver disease. Gut 1998;42:10711 .

28 Hollingsworth RC, Minton EJ, Fraser-Moodie C, et al. Hepatitis $\mathrm{G}$ infection: role in cryptogenic chronic liver disease and primary liver cell cancer in the UK. Trent hepatitis C virus study group. F Viral Hepat 1998;5:165-9.

29 Pessoa MG, Terrault NA, Detmer J, et al. Quantitation of hepatitis $G$ and $C$ viruses in the liver: evidence that hepatitis $\mathrm{G}$ virus is not hepatotropic. Hepatology 1998;27:877-80.

30 Czaja AJ. The variant forms of autoimmune hepatitis. Ann Intern Med 1996;125:588-98. 